\title{
ANALISIS ORIENTASI KEWIRAUSAHAAN NELAYAN TANGKAP SKALA KECIL DENGAN ALAT TANGKAP "JUBI" DI KELURAHAN BATULUBANG KECAMATAN LEMBEH SELATAN KOTA BITUNG
}

\author{
Cindy L.M. Sanger'; Alvon Jusuf2; Jardie A. Andaki² \\ 1)Mahasiswa Fakultas Perikanan dan IImu Kelautan Universitas Sam Ratulangi Manado \\ 2)Staff Pengajar Fakultas Perikanan dan IImu Kelautan Universitas Sam Ratulangi Manado \\ Koresponden email : cindylmsanger@yahoo.co.id
}

\begin{abstract}
This study aims to find out two things. First, the entrepreneurial orientation of small-scale fishermen with jubi fishing gear at Batulubang District. Second, dimensions that have a large role in their entrepreneurial orientation. This research was conducted by survey method with a sample of 30 respondents who were captured fishermen using jubi fishing gear (arrows). Primary data collection is done by using questionnaires and interviews and secondary data collected by researchers from documents published by several relevant agencies, especially the Batulubang Village and the North Sulawesi Province's Office of Maritime Affairs and Fisheries, Bitung City Marine and Fisheries Office and Central Bureau of Statistics Bitung City, especially those related to data on capture fisheries in Bitung City. Data were then analyzed using descriptive statistical methods. The results of this study indicate that the entrepreneurial orientation of small-scale fishermen with archery gear at Batulubang Overall is classified as moderate. The results of further analysis show that the dimensions of independence and the dimensions of their innovativeness are also high, but the dimensions of risk taking and the dimensions of their activity are classified as moderate. The conclusion of this study is that the entrepreneurial orientation of small-scale fishermen with jubi fishing gear in the Batulubang Overall is relatively moderate.
\end{abstract}

Key Words: Entrepreneurship orientation, fishermen, jubi fishing gear, Batulubang Village

\begin{abstract}
Abstrak
Penelitian ini bertujuan untuk mengetahui dua hal. Pertama, orientasi kewirausahaan para nelayan skala kecil dengan alat tangkap jubi di Keluruhan Batulubang. Kedua, dimensi-dimensi yang memiliki peranan besar dalam orientasi kewirausahaan mereka. Penelitian ini dilaksanakan dengan metode survei dengan sampel sebanyak 30 orang responden yang merupakan nelayan tangkap dengan menggunakan alat tangkap jubi (panah). Pengumpulan data primer dilakukan dengan menggunakan kuesioner dan wawancara dan data sekunder yang dikumpulkan oleh peneliti dari dokumen-dokumen yang diterbitkan oleh beberapa instansi terkait, khususnya Kelurahan Batulubang dan Dinas Kelautan dan Perikanan Provinsi Sulawesi Utara, Dinas Kelautan dan Perikanan Kota Bitung dan Biro Pusat Statistik (BPS) Kota Bitung, khususnya yang terkait dengan data mengenai perikanan tangkap di Kota Bitung. Data kemudian dianalisis dengan menggunakan metode statistik deskriptif. Hasil penelitian ini menunjukkan bahwa orientasi kewirausahaan nelayan skala kecil dengan alat tangkap panahan di Keluruhan Batulubang tergolong sedang. Hasil analisis lebih ranjut menunjukkan dimensi kemandirian dan dimensi keinovatifan mereka juga tergolong tinggi, namun dimensi pengambilan resiko dan dimensi keproaktifan mereka tergolong sedang. Kesimpulan penelitian ini adalah orientasi kewirausahaan nelayan skala kecil dengan alat tangkap jubi di Keluruhan Batulubang secara umum tergolong sedang.
\end{abstract}

Kata Kunci: Orientasi Kewirausahaan, nelayan, alat tangka jubi, Kelurahan Batulubang

\section{PENDAHULUAN}

Perikanan skala kecil mempunyai peranan penting dalam perekonomian baik dalam aspek makro maupun mikro. Dalam perspektif sosial ekonomi, masyarakat pesisir sebagian besar tergantung pada sumberdaya perikanan laut. Perikanan tangkap mempunyai peranan penting dalam menopang ketahanan pangan Indonesia, terutama dalam hal penyediaan ikan. Dengan semakin meningkatnya konsumsi ikan per kapita di Indonesia, sehingga menyebabkan kebutuhan terhadap ikan juga mengalami peningkatan, sehingga mengakibatkan kegiatan produksi perikanan tangkap juga menjadi pesat (Purnomo, 2012).

Indonesia sebagai negara kepulauan memiliki sumberdaya alam terbesar yaitu pada bidang kelautannya, terutama hasil dari sektor perikanan lautnya. Sumberdaya alam tersebut merupakan sebuah potensi yang sangat menguntungkan apabila dikelola secara baik dan benar, dengan kata lain disini adalah kita juga harus ikut menjaga dan memperhatikan ekosistem 
yang hidup di laut, agar kelestariannya tetap terpelihara dan kita juga tetap dapat menikmati hasil laut dari laut tersebut.

\section{Orientasi}

kewirausahaan

(enterpreneutrial orientation) adalah orientasi perusahaan yang memiliki prinsip pada upaya untuk mengidentifikasi dan mengeksploitasi kesempatan (Lee \& Chu, 2011). Selanjutnya Suardhika, (2012), menjelaskan lebih lanjut bahwa orientasi kewirausahaan adalah orientasi untuk menjadi yang pertama dalam hal inovasi, memiliki sikap mengambil resiko, dan proaktif terhadap perubahan yang terjadi pada suatu usaha. Pelaku usaha yang memiliki orientasi kewirausahaan yang kuat akan memiliki kemampuan untuk melakukan inovasi lebih kuat, lebih berani untuk mengambil resiko, dan tidak hanya bertahan pada strategi masa lalu. Pada lingkungan yang dinamis seperti saat ini, orientasi kewirausahaan jelas merupakan hal yang sangat penting bagi kelangsungan hidup perusahaan atau usaha yang dikelola oleh pelaku usaha.

Perkembangan dunia usaha menuntut setiap perusahaan maupun pelaku usaha untuk bersaing dan tetap mempertahankan eksistensinya di era globalisasi. Persaingan dalam dunia usaha yang tidak terkendali seringkali membawa konsekuensi negatif bagi lingkungan dunia usaha. Perusahaan membutuhkan suatu sumberdaya penting yang seharusnya dapat menjadi komponen pendukung sekaligus sebagai kekuatan bahkan sebagai keunggulan bersaing secara berkelanjutan.

Menurut Covin (1991) dan Miles et all. (2000), orientasi kewirausahaan adalah refleksi dari sikap perilaku strategis perusahaan, yang mencakup inisiatif untuk berinovasi, pengambilan keputusan beresiko, dan bersikap proaktif dalam persaingan. Dengan demikian, orientasi kewirausahaan dapat berperan sebagai bagian dari perilaku perusahaan yang memiliki hubungan erat dengan kinerja perusahaan.

Salah satu alat tangkap tradisional yang sebagian besar dipakai oleh nelayan Indonesia adalah jubi (panah). Dengan wilayah perairan yang begitu luas dan terdiri dari bermacam-macam jenis perairan hal ini berdampak pada jenis alat tangkap yang begitu beragam pula. Ada jenis alat tangkap yang digunakan di laut adapula yang digunakan di perairan umum. Dari alat tangkap yang tradisional sampai yang modern, dari alat tangkap yang mahal sampai kealat tangkap yang sederhana. Karena kemajuan teknologi yang begitu pesat maka alat tangkap yang sederhana akan tetapi memiliki berbagai keuntungan seperti panahan kini mulai menghilang. Alat tangkap jubi sebagai alat tangkap lebih ramah lingkungan daripada menggunakan trawl (jaring). Selain kontruksinya sederhana, metode pengoprasian mudah, tidak memerlukan modal yang besar dan perahu khusus (Von Brandt, 1984 dalam Sudirman dan Mallawa, 2004).

Kota Bitung memiliki peranan dalam produksi ikan nasional yang merupakan komoditas ekspor utama (Kota Bitung Dalam Angka 2014). Menurut Witomo dan Wardono (2012), perikanan tangkap merupakan salah satu kegiatan ekonomi yang sangat penting di Kota Bitung. Pada usaha kecil, perilaku perusahaan tercermin dari perilaku pemilik usaha yang umunya merangkap sebagai manajer atau pengelolaan.

Keberhasilan penangkapan ikan karang sangat dipengaruhi oleh teknik pengoperasian dari pemancing untuk mendapatkan hasil yang maksimal. Perkembangan alat tangkap ikan terus berkembang dari segi perubahan bentuk, model, serta cara pengoperasian, salah satunya jubi. Alat tangkap ikan sebagai sarana utama dalam pemanfaatan ikan diatur sedemikian rupa sehingga tidak berdampak negatif baik pada pemanfaat dan 
pengguna sumberdaya ikan, biota, dan lingkungan perairan serta pengguna jasa perairan lainnya. Penggunaan alat tangkap ikan dalam pemanfaatan sumberdaya ikan harus benar-benar memperhatikan keseimbangan dan meminimalkan dampak negatif bagi biota lain yang kurang termanfaatkan.

\section{METODE PENELITIAN}

Metode yang dipakai dalam penelitian ini dipakai metode survei. Menurut Jupp. V. The Sage Dictionary of Social Research Methods. (2006), survei adalah suatu pendekatan dalam penelitian yang mengumpulkan data mengenai suatu unit analisis, biasanya individu atau orang, dengan menggunakan teknik sampling (pengambilan contoh).

Dalam penelitian ini data primer dikumpulkan oleh peneliti melalui wawancara terstruktur berdasarkan kuesioner yang telah disiapkan sebelumnya. Untuk mendapatkan hasil observasi mengenai orientasi kewirausahaan nelayan skala kecil dengan alat jubi diperlukan 30 responden dengan jumlah populasi kurang lebih 50 orang. Responden yang diambil dalam analisis orientasi kewirausahaan nelayan skala kecil dengan alat tangkap jubi yaitu nelayan yang melalukan pencarian ikan menggunakan alat tangkap jubi.

Untuk menjawab item-item yang berkaitan dengan derajat atau kecenderungan beberapa variabel dalam penelitian ini digunakan pertanyaan atau pernyataan yang sederhana. Masing-masing pertanyaan atau pernyataan tersebut disajikan beserta alternatif-alternatif jawaban yang mengikuti skala Likert $1-5$. Sekaran, 2006, yaitu:

1. Sangat Tidak Setuju (skor 1),

2. Tidak Setuju (skor 2),

3. Ragu-ragu/Netral (skor 3),

4. Setuju (skor 4), dan

5. Sangat Setuju (skor 5)
Penentuan variable dalam penelitian ini, dibagi dalam dimensi dan indikator guna menentukan orientasi kewirausahaan nelayan skala kecil dengan alat tangkap "jubi".

Data primer yang dikumpulkan melalui kuesioner ditabulasi untuk mendapatkan nilai skor pada setiap jawaban. Selanjutnya data primer tersebut diolah dengan langkahlangkah sebagai berikut:

1. Menghitung frekuensi jawaban responden dengan skor 1 sampai skor 5 untuk setiap item atau indikator dalam kuesioner.

2. Menghitung persentase jawaban responden dengan skor 1 sampai skor 5 untuk setiap item atau indikator dalam kuesioner.

3. Menghitung rataan setiap indikator dalam masing-masing dimensi Orientasi Kewirausahaan dengan rumus: ((\% skor 1) $\times 1)+((\%$ skor 2$) \times 2)+((\%$ skor 3$) \times$ $3)+((\%$ skor 4$) \times 4)+((\%$ skor 5$) \times 5)$.

4. Menghitung rataan masing-masing dimensi Orientasi Kewirausahaan berdasarkan nilai rataan masing-masing indikator yang membentuknya.

5. Menghitung rataan komposit variabel Orientasi Kewirausahaan berdasarkan nilai rataan masing-masing dimensi yang membentuknya.

6. Menentukan kisaran (range) nilai skor dimensi yang tergolong rendah, sedang dan tinggi berdasarkan nilai kisaran skor terendah dan skor tertinggi dan kemudian dibagi tiga.

7. Menentukan persentase (\%) jumlah responden pada masing-masing dimensi dan variabel yang masuk dalam kategori rendah, sedang dan tinggi. 


\section{HASIL DAN PEMBAHASAN}

\section{Nelayan Batulubang}

Masayarakat yang mempunyai mata pencaharian dan berpenghasilan sebagai nelayan merupakan salah satu dari kelompok masyarakat yang melakukan aktivitas usaha dengan mendapat penghasilan bersumber dari kegiatan nelayan itu sendiri. Nelayan adalah orang yang secara aktif melakukan pekerjaan dalam operasi penangkapan ikan. Tingkat kesejahteraan nelayan sangat ditentukan oleh hasil tangkapannya. Banyaknya tangkapan tercermin pula besarnya pendapatan yang diterima dan pendapatan tersebut sebagian besar untuk keperluan kebutuhan keluarga.

Nelayan Keluarahan Batulubang, pendapatan yang dihasilkan oleh satu kali perjalanan melaut adalah pendapatan bersih, yaitu pendapatan yang sudah dikurangi dengan beban-beban operasional yang ditanggung oleh pemilik perahu. Bahan bakar dan biaya operasional perahu yang sudah menjadi tanggung jawab pemilik perahu.

Perahu yang digunakan disebut perahu pelang/londe yang dinaiki oleh 4 (empat) orang jika perahu yang besar sedangkan yang kecil 2 (dua) orang. Adapun jenis tangkapan ikan yang didapat pada nelayan Batulubang adalah kakap, kerapu, kakatua, gurita dan Tobster. Alat tangkap yang digunakan yaitu menggunakan alat tangkap jubi.

Kontruksi alat tangkap jubi sangat sederhana pada dasarnya terdiri dari dua bagian yaitu kerangka alat tangkap anak panah, pipa pelotar, karet pelontar, snap, pengait anak panah. Sarana pendukung operasi penangkapan adalah perahuukuran $8 \times 1,2 \times 1,2$ meter, box pendingin, kompresor, selang udara, peralatan selam, pemberat, senter selam. Jumlah nelayan dalam perahu dalam melakukan penangkapan adalah $2-4$ orang.
Daerah penangkapan ikan yang dipilih adalah daerah yang memiliki terumbu karang atau perairan dekat dengan pulau sekitar 1-2 km dari pantai. Tujuan dipilihya daerah terumbu karang dekat pantai adalah untuk memilih daerah yang aman dilakukan operasi penangkapan dan sasaran utama adalah ikan karang. Daerah yang dipilih adalah perairan yang tidak terlalu dalam yaitu sekitar 35-40 meter.

Penangkapan ikan menggunakan alat tangkap jubi biasanya dilakukan pada sore hari sekitar jam 16.00 hingga terbit fajar pada pukul 05.00. Lama trip melaut ini dianggap juga one day fishing. Tahap operasi penangkapan adalah.

1. Persiapan: Tahap mempersiapkan perbekalan operasi dan pengecekkan sasaran operasi.

2. Pencarian (fishing ground): pencarian dilakukan pada sore hari, dan nelayan menunggu sampai gelap.

3. Operasi Penangkapan: Tahap ini pembagian tugas ada 2 yaitu nelayan penyelam 1-3 orang dan nelayan penjaga kompressor 1-2 orang.

Nelayan melakukan penyelaman 2-3 kali dalam satu malam. Lama penyelaman 23 jam tergantung dari kondisi perairan. Setelah dilakukan penyelaman proses berikutnya adalah memindahkan ikan dari kantong jaring yang dibawa nelayan penyelam ke box penyimpanan yang sudah berisi es. Nelayan penyelam istirahat di kapal sekitar 30-45 menit kemudian melakukan penyelaman lagi. Hal ini terus berulang hingga terbit fajar dan nelayan siap pulang ke rumah.

Daerah tempat menangkap ikan ternyata nelayan Kelurahan Batulubang harus melihat mata angin jika angin selatan daerah penangkapan batu putih dan jika angin barat daerah penangkapan di lembeh. Ikan yang didapat diambil oleh seorang nelayan pengumpul untuk dijual dipasar. 


\section{Kehidupan Nelayan Batulubang}

Nelayan merupakan kelompok masyarakat yang mata pencahariannya sebagian besar bersumber dari aktivitas menangkap ikan dan mengumpulkan hasil laut lainnya. Nelayan Batulubang rata-rata memiliki waktu melaut bervariatif, antara 1 (satu) hari 1 (satu) kali melaut dan 1 (satu) minggu 3 (tiga) kali melaut untuk jam pergi melaut yaitu pukul 16.00 (4 sore) dan pulang pukul 05.00 (5 pagi).

Hasil tangkapan setiap nelayan bervariatif, tergantung jenis perahu dan perairan yang mereka datangi. Semakin besar jenis perahu yang mereka miliki, maka kemungkinan untuk mendapatkan ikan juga semakin besar. Pengalaman melaut juga berpengaruh terhadap hasil tangkapan ikan. Nelayan yang sudah memiliki pengalaman maka sudah memiliki kemampuan yang cukup untuk diandalkan dalam menangkap ikan. Nelayan Batulubang sudah memiliki perhitungan untuk melaut, setiap hari selasa, rabu, kamis dan jumat.
Dapat dilihat pada tabel 7 pendapatan per/tahun dalam melakukan pencarian ikan dengan menggunakan alat tangkap jubi.

Pendapatan nelayan tangkap dengan menggunakan alat tangkap jubi per tahun pendapatan nelayan perahu besar dengan jumlah 17 orang mendapatkan pendapatan 7,6 - 9,4juta, sedangkan nelayan perahu kecil dengan jumlah 13 orang mendapatkan pendapatan $6,4-7,8$ juta. Pendapatan yang didapatkan dalam tabel 7. Selama 8 bulan, ada beberapa bulan tidak dapat melaut karena faktor cuaca dan ada perahu dalam kondisi perbaikan.

Tabel 1. Pendapatan Nelayan di Kelurahan Batulubang

\begin{tabular}{|c|c|c|c|}
\hline No & $\begin{array}{c}\text { Pendapatan } \\
(\mathrm{Rp})\end{array}$ & $\begin{array}{c}\text { Jumlah } \\
\text { (orang) }\end{array}$ & $\begin{array}{c}\text { Persentase } \\
(\%)\end{array}$ \\
\hline 1. & $7,6-9,4$ juta & 17 & 57 \\
\hline 2. & $6,4-7,8$ juta & 13 & 43 \\
\hline & Jumlah & 30 & 100 \\
\hline
\end{tabular}

Sumber: Data diolah, 2019

\section{Orientasi Kewirausahaan Nelayan Skala Kecil dengan Alat Tangkap "JUBl"}

Orientasi kewirausahaan pada hasil penelitian ini, disajikan pada Tabel 2.

Tabel 2. Orientasi Kewirausahaan Nelayan Skala Kecil dengan Alat Tangkap “JUBI” di Kelurahan Batulubang, Kecamatan Lembeh Selatan, Kota Bitung

\begin{tabular}{|c|c|c|c|c|c|c|c|c|c|c|c|c|c|}
\hline \multirow{3}{*}{ Dimensi } & \multirow{3}{*}{ Indikator } & \multirow{2}{*}{\multicolumn{2}{|c|}{ Skor 1}} & \multirow{2}{*}{\multicolumn{2}{|c|}{$\begin{array}{l}\text { Variabel } \\
\text { Skor } 2\end{array}$}} & Orie & tasi Kel & aus & aan) & & & & \\
\hline & & & & & & \multicolumn{2}{|c|}{ Skor 3} & \multicolumn{2}{|c|}{ Skor 4} & \multicolumn{2}{|c|}{ Skor 5} & \multirow{2}{*}{$\begin{array}{l}\text { Rataan } \\
\text { Indikator }\end{array}$} & \multirow{2}{*}{$\begin{array}{l}\text { Rataan } \\
\text { Dimensi }\end{array}$} \\
\hline & & $\mathrm{F}$ & $\%$ & $\mathrm{~F}$ & $\%$ & $\mathrm{~F}$ & $\%$ & $\mathrm{~F}$ & $\%$ & $\mathrm{~F}$ & $\%$ & & \\
\hline \multirow{3}{*}{$\mathrm{X} 1$} & $\mathrm{X} 11$ & 0 & $0.0 \%$ & 0 & $0.0 \%$ & 16 & $53.3 \%$ & 14 & $46.7 \%$ & 0 & $0.0 \%$ & 3.47 & \multirow{3}{*}{3.68} \\
\hline & $\mathrm{X} 12$ & 0 & $0.0 \%$ & 0 & $0.0 \%$ & 10 & $33.3 \%$ & 19 & $63.3 \%$ & 1 & $3.3 \%$ & 3.70 & \\
\hline & $x 13$ & 0 & $0.0 \%$ & 0 & $0.0 \%$ & 5 & $16.7 \%$ & 24 & $80.0 \%$ & 1 & $3.3 \%$ & 3.87 & \\
\hline \multirow{3}{*}{$\mathrm{X} 2$} & X21 & 0 & $0.0 \%$ & 0 & $0.0 \%$ & 1 & $3.3 \%$ & 29 & $96.7 \%$ & 0 & $0.0 \%$ & 3.97 & \multirow{3}{*}{3.93} \\
\hline & $\times 22$ & 0 & $0.0 \%$ & 0 & $0.0 \%$ & 2 & $6.7 \%$ & 28 & $93.3 \%$ & 0 & $0.0 \%$ & 3.93 & \\
\hline & $\times 23$ & 0 & $0.0 \%$ & 0 & $0.0 \%$ & 3 & $10.0 \%$ & 27 & $90.0 \%$ & 0 & $0.0 \%$ & 3.90 & \\
\hline \multirow{3}{*}{ X3 } & X31 & 0 & $0.0 \%$ & 7 & $23.3 \%$ & 7 & $23.3 \%$ & 16 & $53.3 \%$ & 0 & $0.0 \%$ & 3.30 & \multirow{3}{*}{3.16} \\
\hline & X32 & 0 & $0.0 \%$ & 0 & $0.0 \%$ & 28 & $93.3 \%$ & 2 & $6.7 \%$ & 0 & $0.0 \%$ & 3.07 & \\
\hline & X33 & 0 & $0.0 \%$ & 0 & $0.0 \%$ & 27 & $90.0 \%$ & 3 & $10.0 \%$ & 0 & $0.0 \%$ & 3.10 & \\
\hline \multirow{3}{*}{$X 4$} & X41 & 0 & $0.0 \%$ & 1 & $3.3 \%$ & 22 & $73.3 \%$ & 7 & $23.3 \%$ & 0 & $0.0 \%$ & 3.20 & \multirow{3}{*}{3.31} \\
\hline & $X 42$ & 0 & $0.0 \%$ & 5 & $16.7 \%$ & 19 & $63.3 \%$ & 3 & $10.0 \%$ & 3 & $10.0 \%$ & 3.13 & \\
\hline & $\mathrm{X} 43$ & 0 & $0.0 \%$ & 0 & $0.0 \%$ & 15 & $50.0 \%$ & 12 & $40.0 \%$ & 3 & $10.0 \%$ & 3.60 & \\
\hline
\end{tabular}

Sumber: Data diolah, 2019

Variabel Orientasi Kewirausahaan $(X)$ diukur oleh empat dimensi, yaitu Kemandirian $\left(X_{1}\right)$, Keinovatifan $\left(X_{2}\right)$, Pengambilan Resiko $\left(X_{3}\right)$ dan Keproaktifan $\left(\mathrm{X}_{4}\right)$. Masing-masing dimensi tersebut diukur dengan tiga indikator, sehingga secara keseluruhan pengukuran variabel Orientasi Kewirausahaan ini melibatkan 12 indikator. Hasil analisis deskriptif terhadap jawaban responden mengenai orientasi 
kewirausahaan mereka disajikan pada Tabel 2.

Hasil analisis pada Tabel 2 menunjukkan skor rata-rata tiap indikator berada pada rentang 3,07 - 3,97 sehingga dapat dikatakan indikator-indikator berada pada kategori sedang dan tinggi. Dari 12 indikator yang digunakan sebagai pengukur variabel Orientasi Kewirausahaan, yang mendapatkan skor tertinggi adalah indikator X21 ("suka berinovasi dengan mencoba halhal yang baru") dengan rata-rata 3,97, adalah indikator X22 ("suka memanfaatkan peluang usaha yang baru") dengan rata-rata 3,93, dan indikator X23 ("suka mencari informasi baru yang terkait dengan usaha mereka") dengan rata-rata 3,90.

Ketiga indikator tersebut semuanya merupakan bagian dari dimensi
Keinovatifan. Di lain pihak, indikatorindikator yang mendapatkan skor terendah adalah X32 ("konsekuen dalam berusaha, walaupun sempat merugi") dengan rata-rata 3,07, X33 ("berani berinvestasi di bidang usaha perikanan tangkap, walaupun dengan berhutang") dengan rata-rata 3,10, dan X42 ("aktif dalam menghadapi tantangan persaingan dalam menjalankan usaha") dengan rata-rata 3,13 . Dua indikator dengan skor rata-rata terendah, yaitu X32 dan X33 merupakan bagian dari dimensi Pengambilan Resiko, sedangkan satu indikator lainnya yaitu X42 merupakan bagian dari dimensi Keproaktifan. Hasil penilaian setiap indikator dan dimensi disajikan secara lengkap pada Tabel 2.

Tabel 3. Hasil Penilaian Indikator dan Dimensi dari Variabel Orientasi Kewirausahaan

\begin{tabular}{|c|c|c|c|c|c|}
\hline \multicolumn{6}{|c|}{ Variabel (Orientasi Kewirausahaan) } \\
\hline Dimensi & Indikator & Rataan Indikator & Kategori Indikator & Rataan Dimensi & Kategori Dimensi \\
\hline \multirow{3}{*}{$\mathrm{X} 1$} & $\mathrm{X} 11$ & 3.47 & Sedang & \multirow{3}{*}{3.68} & \multirow{3}{*}{ Tinggi } \\
\hline & $\mathrm{X} 12$ & 3.70 & (Jinggi & & \\
\hline & $\mathrm{X} 13$ & 3.87 & Tinggi & & \\
\hline \multirow{3}{*}{$\mathrm{X} 2$} & $\mathrm{X} 21$ & 3.97 & Tinggi & \multirow{3}{*}{3.93} & \multirow{3}{*}{ Tinggi } \\
\hline & $\mathrm{X} 22$ & $3.93 \bigcirc$ & Tinggi & & \\
\hline & $\mathrm{X} 23$ & 3.90 & Tinggi & & \\
\hline \multirow{3}{*}{$\mathrm{X} 3$} & $\mathrm{X} 31$ & 3.30 & Sedang & \multirow{3}{*}{3.16} & \multirow{3}{*}{ Sedang } \\
\hline & X32 & 3.07 & Sedang & & \\
\hline & X33 & 3.10 & Sedang & & \\
\hline \multirow{3}{*}{$\mathrm{X} 4$} & $\mathrm{X} 41$ & 3.20 & Sedang & \multirow{3}{*}{3.31} & \multirow{3}{*}{ Sedang } \\
\hline & $\mathrm{X} 42$ & 3.13 & Sedang & & \\
\hline & $\mathrm{X} 43$ & 3.60 & Sedang & & \\
\hline
\end{tabular}

Sumber: Data diolah, 2019

Hasil analisis ini menunjukkan bahwa dimensi Kemandirian (X1) nelayan pemilik alat tangkap di Kelurahan Batulubang tergolong tinggi dengan skor rata-rata 3,68. Demikian juga, dimensi Keproaktifan (X2) para nelayan tersebut tergolong tinggi dengan skor rata-rata 3,93. Namun demikian, dimensi Pengambilan Resiko (X3) para nelayan tersebut tergolong sedang dengan skor rata-rata 3,16. Dimensi Keproaktifan mereka juga tergolong sedang dengan skor rata-rata 3,31.
Secara keseluruhan, Orientasi Kewirausahaan para nelayan pemilik alat tangkap di Kelurahan Batulubang termasuk dalam kategori sedang berdasarkan rata-rata nilai masingmasing dimensi $(3,52)$. Agar Orientasi Kewirausahaan para nelayan tersebut dapat meningkat, maka perlu upaya untuk mendorong mereka untuk lebih berani mengambil resiko dan juga lebih proaktif dalam mengantisipasi perubahan, menghadapi tantangan, dan bertindak cepat bertindak mengatasi masalah yang urgen. 


\section{KESIMPULAN}

Berdasarkan hasil penelitian dan pembahasan dapat disimpulkan dua hal sebagai berikut:

1. Orientasi kewirausahaan nelayan skala kecil dengan alat tangkap jubi di Keluruhan Batulubang secara umum tergolong sedang.

2. Kemandirian dan keinovatifan mereka juga tinggi, namun keberanian dalam pengambilan resiko dan keproaktifan mereka tergolong sedang.

\section{DAFTAR PUSTAKA}

Badan Pusat Statistik dan Bappeda Kota Bitung. 2004. Laporan Tahunan Bitung dalam Angka Tahun 2014.

Covin, J.G., D. Slevin., 1991. A Conceptual Model of Entrepreneurship as Firm Behavior, Baylor University.

Food Agriculture Organization (FAO). 2005. The State of World Fisheries and Agriculture (SOFIA). FAO.

Kumalaningrum, M.P., 2012. Lingkungan Bisnis, Orientasi Kewirausahaan, Orientasi Pasar dan Kinerja Usaha Mikro, Kecil $\diamond$ dan Menengah. Jurnal Riset Manajemen dan Bisnis.

Lee, T.K., Wenyi Cu. 2012. Entrepreneurial orientation and competitive advantage: The mediation of resource value and raraness. African Journal of Business Management.

Lumpkin, G.T., C.C Cogliser., D.R Schneider., 2009. Understanding and Measuring Autonomy: An Entrepreneurial Orientation. Entrepreneurship Theory and Practice, Volume 33, Issue 1, pp. 47-69.

Lumpkin, G.T., G.G Dess., 1996 Clarifying the entrepreneurial orientation construct and lingking it to performance. Academy of Management Review.

Mantjoro, E., 1993. Ekonomi Sumberdaya Perikanan, Pengantar Ekonomi Sumberdaya Perikanan. Lab. Ekonomi dan Bisnis Perikanan FPIK Unsrat. Manado.

Mulyadi, 2005. Ekonomi Kelautan. PT Raja Grafindo. Jakarta.

Nasution, Z., T.T Sastrawidjaja., F.N Hartono., Priyatna, dan Mursidin, 2007. Sosial Budaya
Masyarakat Nelayan: Konsep dan Indikator Pemberdayaan. Badan Riset Kelautan dan Perikanan, Departemen Kelautan dan Perikanan. Jakarta.

Nontji, A, 1993. Laut Nusantara. Penerbit Djambatan. Jakarta

Nursalam, S Pariani., 2001. Pendekatan Praktis Metodelogi Riset Keperawatan. Jakarta: Penerbit Salemba Medika.

Nybakken, J.W., 1988. Suatu Pendekatan Ekologis. Jakarta: Penerbit PT. Gramedia.

Pangeran, P., 2012. Orientasi Pasar, Orientasi Kewirausahaan dan Kinerja Keuangan Pengembangan Produk Baru Usaha Mikro Kecil dan Menengah. Jurnal Riset Manajemen dan Bisnis.

Prasetyo, C.T, 2012. Analisis Pengaruh Orientasi Kewirausahaan dan Motivasi Wirausaha Terhadap Kinerja Bisnis, Journal Universitas Diponegoro.

Purnomo, B.H., 2012. Peranan Perikanan Tangkap Berkelanjutan untuk Menunjang Ketahanan Pangan di Indonesia. Artikel. Fakultas Teknologi Pertanian Universitas Jember.

Salas, S., D Gaertner., 2004. The Behavioural Dynamics of Fisheries. : Management Implications. Fish and Fisheries.

Sekaran, U., 2006. Research Methods for Business (Metode Penelitian Untuk Bisnis). Penerbit Salemba Empat, Jakarta.

Singarimbun, M., S Effendi., 2008. Metode Penelitian Survei. Jakarta: LP3ES.

Suardhika, I.N., 2012. Model Integrasi dalam RBV untuk Penerapan Strategi Bersaing dan Pencapaian Kinerja Usaha (Studi pada Usaha Kecil dan Menengah di Bali), Ekuitasi STIESIA Surabaya (Terakreditasi Nasional).

Sudirman, H., A Mallawa., 2004. Teknik Penangkapan Ikan. Penerbit Rineka Cipta, Jakarta.

Sugiyono, 2006. Statistika untuk Penelitian. Bandung: CV. Alfabeta.

Sugiyono, 2016. Metode Penelitian Kuantitatif, Kualitatif dan R \& D. Bandung: PT Alfabeta.

Syarief, E. 2001. Pengembangan Kelautan dalam Konteks Pemberdayaan Masyarakat Pesisir. Majalah PPITh 2001IEidis-25.

Witomo, C.M., B. Warndono., 2012. Potret Perikanan Tangkap Tuna, Cakalang dan Layang di Kota Bitung. Buletin Riset Sosek Kelautan dan Perikanan. 


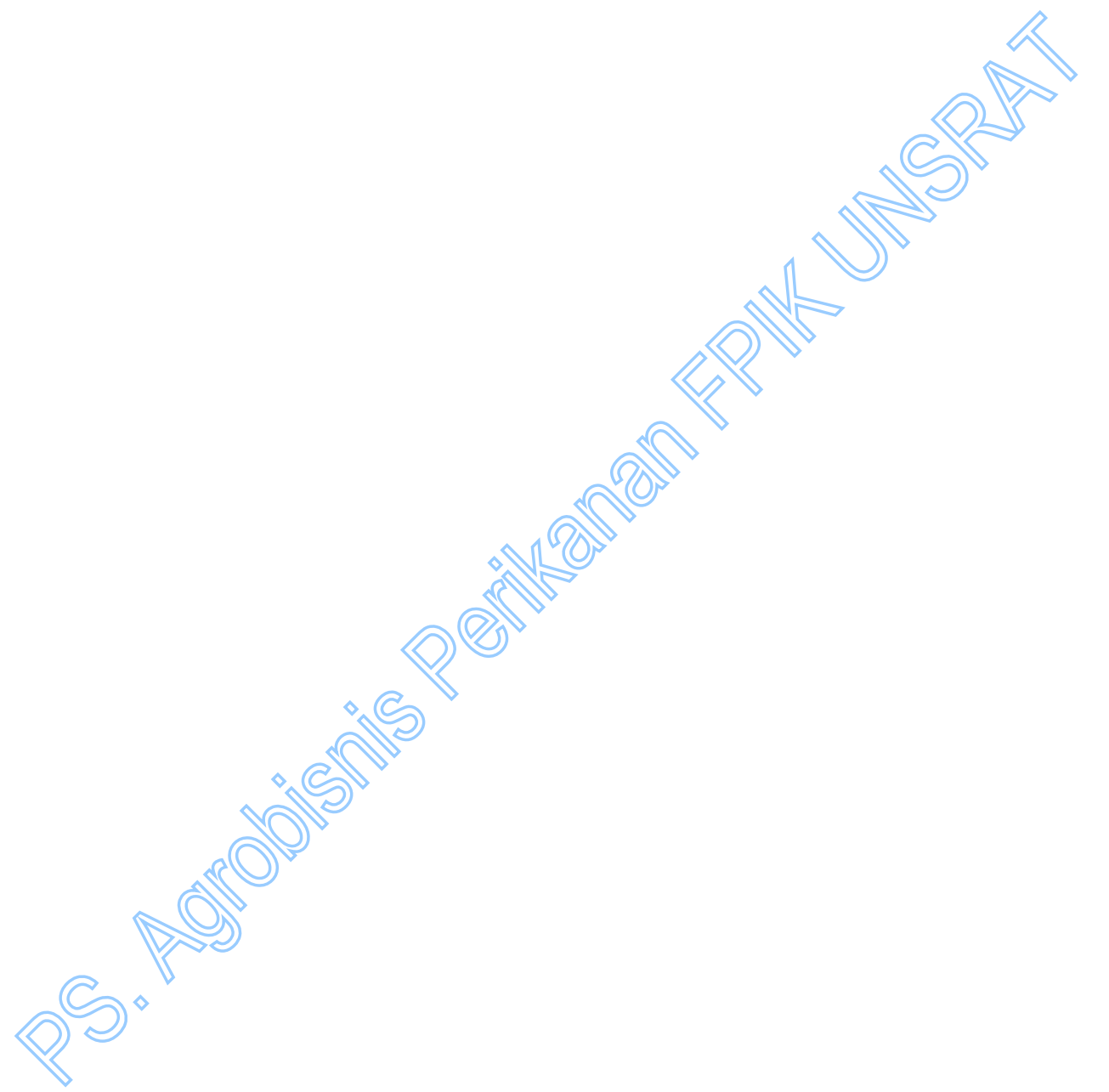

